\title{
A study of communication ties among team members in work environment
}

\author{
Bushra Obeidat* and Bsmah Bany Muhammad \\ Department of Architecture, College of Architecture and Design, Jordan University of Science and Technology, 3030, Irbid 22110, Jordan \\ *Corresponding Author: bbobeidat@just.edu.jo
}

Submitted: $11 / 05 / 2020$

Revised: $\quad 17 / 02 / 2021$

Accepted: $03 / 03 / 2021$

\begin{abstract}
Many organizations are rethinking and redesigning their work environments by moving out from traditional offices to shared team spaces that promote teamwork and collaboration. This study explores communication ties in co-working spaces through a comparative study on Jordanian workplaces and their US counterparts. The study employed spatial analysis and a social network survey to empirically examine the effects of spatial variables (distance and covisibility) and team members' communication characteristics (communication- based on gender and role) on the frequency of employees' face-to-face and electronic-based communications. Correlations and variance analyses indicated that the frequency of communication between two team members declines with the increase of distance between their work locations and increases with the increase of local visual accessibility between them. In a culture characterized by an obvious social hierarchy like Jordan, the frequency of communication among team members with the same role and the same gender was higher than the frequency of communication among team members with different roles or gender.
\end{abstract}

Keywords: Co-working spaces; Open plan office design; Spatial and social analysis; Teamwork; Visibility.

\section{INTRODUCTION}

Workplace planning for new work patterns, particularly for teamwork and collaboration, is increasingly transitioning from the conventional workplace planning approaches, such as segregated individual offices or cubicle walls, to colocated or shared work settings that promote organizational outcomes such as frequent communication, the formation of social ties, innovation, and creativity (Figure 1).

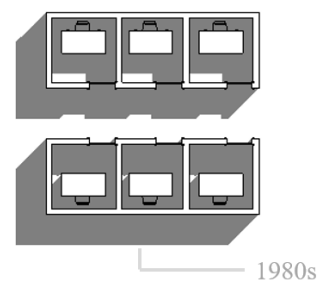

Private Office

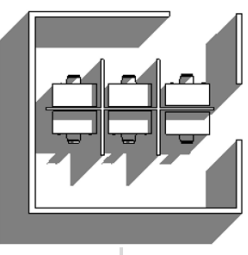

Cubicles

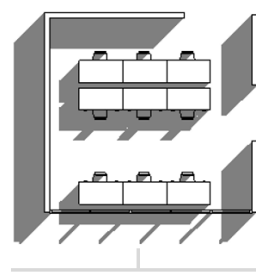

Open Plan

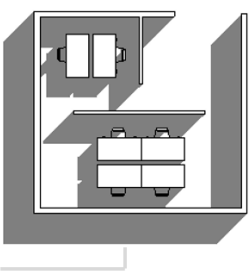

Co-working

Figure 1. Workplace design evolution (author).

Authors have emphasized that workplaces stimulating both work-related and non-work-related communication can support productivity and improve service quality in such organizations. These interpersonal communications also have a direct and indirect impact on staff members, helping mitigate the perceptions of stressful work situations 
(House \& Wells, 1978) and creating a friendly atmosphere in the workplace (Kratzer, Leenders, \& Van Engelen, 2005). Nowadays, communications in work settings are executed through various media, such as telephone, emails, messages, etc. However, face-to-face communication is still the preferred mode in the workplace (Bordia, 1997; Gharaveis, Hamilton, Pati, \& Shepley, 2018; Hollingshead, McGrath, \& O’Connor, 1993; Nardi \& Whittaker, 2002). In an empirical study, Becker-Beck, Wintermantel, and Borg (2005) found that work-teams' performance was better when communicating face-to-face than using computer-mediated tools.

Prior empirical evidence on the effects of coworking spaces on communication and social ties is mixed. On the one hand, scholars have presented a strong argument that removing spatial boundaries between team members increases interaction (Bernstein \& Turban, 2018). Thus, being close to others drives the formation of social ties (Allen, 2007; Tillema, Dijst, \& Schwanen, 2010). This is evident in diverse contexts, such as students' dormitories (Festinger, Schachter, \& Back, 1950), laboratories (Hoegl \& Proserpio, 2004), and coworking spaces in office buildings (Allen, 2007). On the other hand, some scholars have shown that coworking spaces can decrease communication. Their findings suggest that colocation can have negative psychological effects, including reductions in employees' satisfaction, focus, and psychological privacy. Such effects may conceivably discourage interaction between employees (Kim \& De Dear, 2013). The mixed results about the impact of colocation on employees are further related to the varied job requirements (Sundstrom, Town, Brown, Forman, \& Mcgee, 1982). For example, workplaces with private offices are favored in jobs requiring a high level of concentration or, in contrast, shared workspaces are preferred in jobs that involve teamwork and knowledge sharing.

Consequently, research has sought to identify what spatial properties of the physical design impact actual interactions. Visibility and proximity (Figure 2) were among the most frequently cited specific design factors contributing to communication and social ties creation (Gharaveis, Hamilton, \& Pati, 2018). Studies indicated that coworkers' visibility facilitates communication and situation awareness and increases opportunities for knowledgesharing (Appel-Meulenbroek, de Vries, \& Weggeman, 2017; Gharaveis, Hamilton, Pati, et al., 2018; Peponis et al., 2007). Similarly, communication frequency improves with the decrease of distance or the proximity between team members (Allen, 2007; Hoegl \& Proserpio, 2004). Allen (2007) demonstrated that, beyond a distance of about 30 meters, the likelihood of communication becomes minimal.
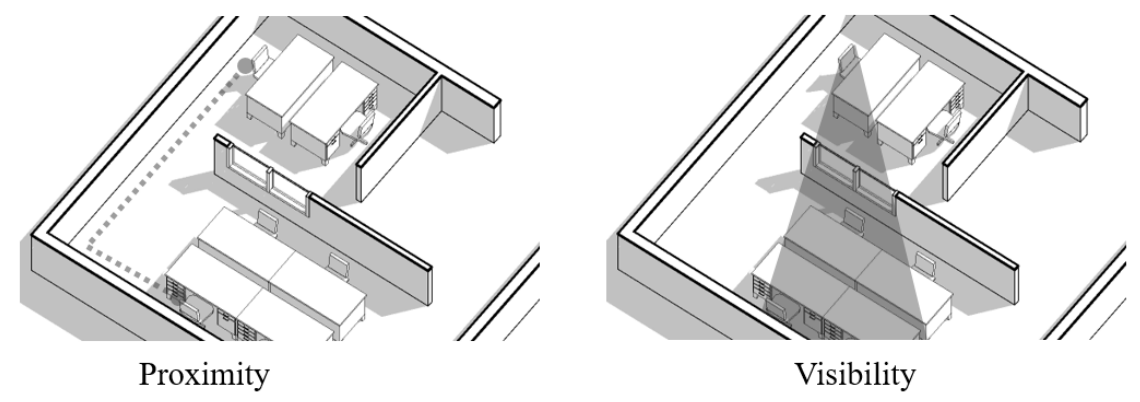

Figure 2. Proximity and visibility (Author).

Proximity and visibility are strong forces in tie creation. However, there is a limitation to this influence, which is the social, cultural, and symbolic features that are intrinsic to the context where social interactions occur. Research on social ties indicates that homophily - the idea of similarity stimulating connections- is a key factor in creating social ties (McPherson, Smith-Lovin, \& Cook, 2001). For example (Figure 3), individuals of the same sex, same educational level, same job position, or same socioeconomic status are more likely to communicate and create social ties than those who are different (McPherson et al., 2001). This tendency of persons to pick partners based on similarity defines communities and their social hierarchies. As Hofstede (2001) explained, in societies with clear vertical hierarchical systems - as with middle eastern societies - people are less likely to connect with persons who are different from themselves. Students, for example, will hesitate to interact with their mentors. Similarly, there will be less opportunity for communication and information exchange between people with different roles/positions in an organization (Hofstede, 2001). 

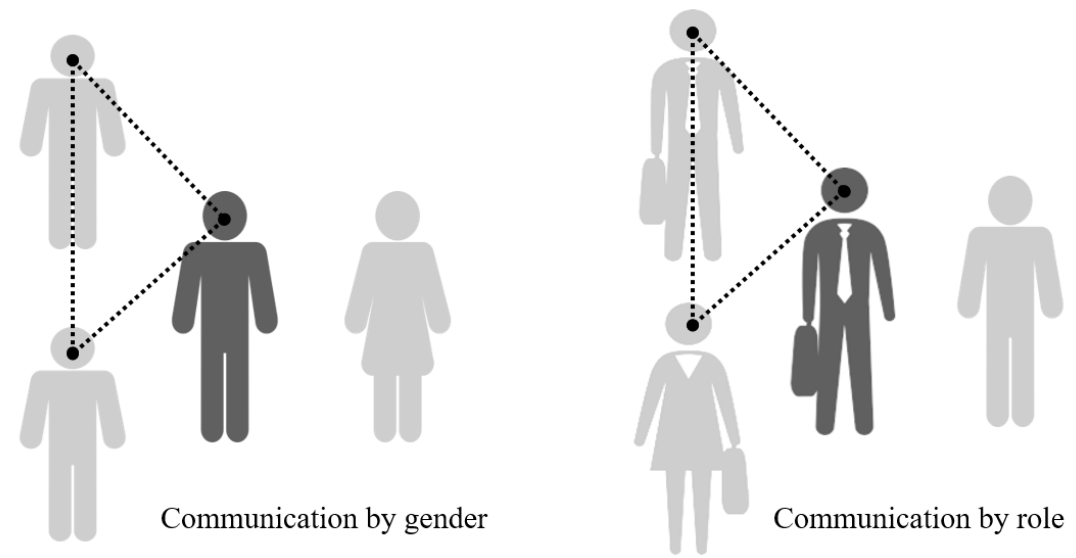

Figure 3. Homophily impacts on communication (Author).

Most of the literature on interpersonal communication in work settings was written in the context of Western culture. However, little research has addressed the impacts of colocation in contexts like Jordan. Interpersonal communications are strongly impacted and regulated by culture (Gudykunst, Ting-Toomey, \& Chua, 1988). Therefore, it is imperative to examine the properties of communication in different contexts. This paper aims to investigate whether the communication network in a colocated workplace still retains certain characteristics of Jordanian sociocultural preferences and how the configurational differences of Jordanian and American workplaces reflect the different communication patterns that are driven by national culture.

The central claim of this paper is that space matters for the dynamics and organizational outcomes of a workplace, such as communications and the formation of social ties. In this exploratory study, we examined the patterns of communication networks among team members in two American and three Jordanian workplaces and addressed three aims. First, we described communication networks that differed according to the context (US and Jordan). Second, using a social network perspective, we examined how two properties of the relationship between individuals - proximity and visibility - influence communication frequency, whether a work-related (routine work conversation) communication or non-work-related communication (personal interests' conversation). We also described how these communication patterns differ according to the type of communication channel (face-to-face or electronic-based communication). Third, we explored how team members' characteristics (specifically gender and role) relate to the frequency of communication using different communication channels or tools.

\section{METHODS}

The research employed spatial analyses and a social network (S.N.) survey to study two American and three Jordanian architectural workplaces with a colocated arrangement. Possible offices were asked to take part, and only ones that agreed to participate were included in the study. Each architecture office comprises small design teams that are less than 20 members. Each team is composed of members of the same specialization but at a different level of seniority. We acknowledge the fact that, due to the selection criteria and small sample size, the five cases are not able to represent the whole population of the US and Jordanian workplaces. However, the analysis of those workplaces does allow us to provide some insights on the role of physical design and team culture in the communication patterns in these two contexts.

\subsection{Setting}

Figure 4 illustrates the layout of the offices and the location of participants in each office. The layout of Office A_USA combines both a shared team area and a set of private offices. Four staff members (33\% out of 12) participated in the social network S.N. survey. The layout of Office B_USA combines two team spaces linked by a circulation 
corridor, and team members are divided between these two spaces. Five staff members (71\% out of 7$)$ participated in the survey; four sat in the same team space. The layout of Office $\mathrm{C}_{-}$Jordan includes a shared team area and a private office. Five staff members participated in the survey (50\% out of 10); four of them sit in the shared team space, and one has a private office. Office D_Jordan combines both private offices and a shared team area. The team area consists of small hubs that include two to three team members. Five members ( $42 \%$ out of 12 ) participated in the survey. Four of them sit in the shared team area, and one has a private office. Office E_Jordan is an open office space where team members' workstations are clustered into two groups. Eight staff members (44\% out of 18) participated in the survey, and all of them are located in the shared team area.

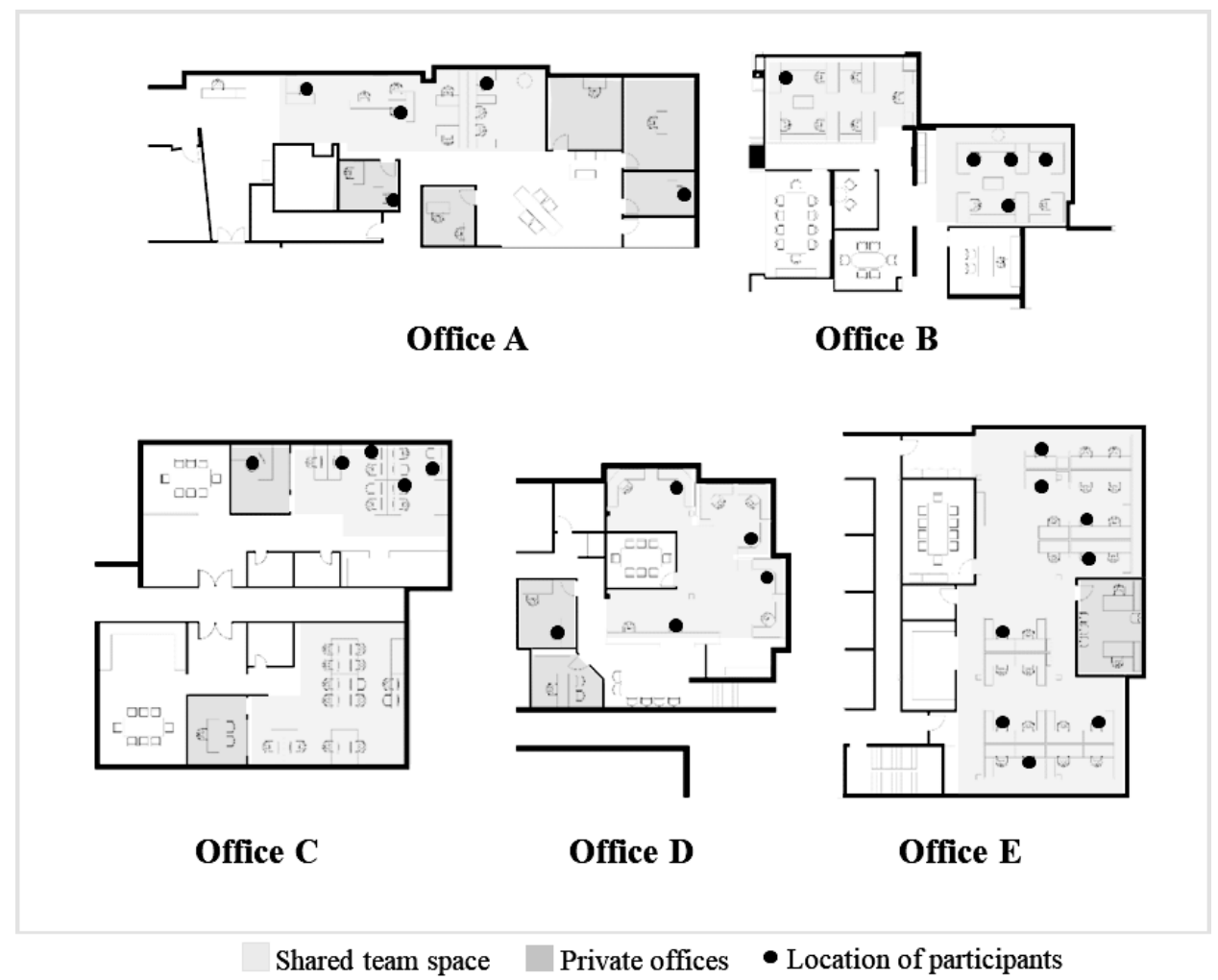

Figure 4. Floor plans of USA workplaces (office A, office B) and Jordanian workplaces (office C, office D, and office E): Workplaces differ in their size and the arrangement of team area (Author).

\subsection{Variables and measures}

\section{Staff communication network}

A social network survey was employed to examine team communication patterns and the structure of social ties that connect a given set of social actors (in our case, team members). The survey asked participants about two types of communication: routine work and personal interest. Respondents were also asked about modes of communication they use for interaction: (face-to-face communication (F2F) and virtual communication (V) (e.g., email, online messages, etc.). For each type and mode of communication (e.g., routine work_F2F, routine work_V), participants were asked to identify a list of people in the office with whom they communicated and then to choose the frequency of communication with each person (e.g. hourly, daily, weekly, or monthly). In social network analysis, data represented in the form of relational matrices (or sociomatrices), in which single observations are given by pairs of social actors, are called dyads. 


\section{Team members' communication characteristics.}

Two communication characteristics (communication-based on gender and communication based on role) were examined in this study. Gender is a salient social category, and its prominence is illustrated by employees' preferences for communication with same-gender or another gender. We defined this communication style as a nominal variable taking the value of (0) when the communication occurs within the same gender and (1) otherwise. The seniority variable described the professional tenures of team members, expressed as the number of years of experience in the field of specialization. In our study, team members represent two groups of employees (seniors and juniors). We defined this communication style as communication by role, where the same role communication was coded by 0 , and different role communication was coded by 1 .

\section{Physical proximity}

Physical proximity represents the distance between two team members. To measure the proximity between workstations, a line was drawn using AutoCAD from the center of one workstation chair to another along the centerline of the accessible route. Then, the length of the shortest distance (measured in meters) was calculated between these two workstations. All values were converted to z-scores for comparison.

\section{Visibility}

Visibility represents the set of all points visible from a given vantage point in the space (Turner, 2011). For spatial analysis, the technique of the visual graph was used. Space syntax scholars have developed the visual graph analysis (VGA), and this has resulted in metrics to describe spatial configurations quantitatively and relate them to users' behaviors (Turner, 2011). Among these metrics are local and global integration, representing the average depth of space to surrounding spaces and all other spaces in the system (Hillier \& Hanson, 1989). These metrics were proven useful in mapping spaces with larger visibility and the possibility of interaction (Penn, Desyllas, \& Vaughan, 1999; Peponis et al., 2007; Sailer \& Penn, 2009; Wineman, Kabo, \& Davis, 2009). All plans were drawn to the same scale (metric) using AutoCAD. In the VGA software UCL Depthmap (Turner, 2011), a 30cm by $30 \mathrm{~cm}$ (1 ft by $1 \mathrm{ft}$ ) grid was overlaid on top of each plan. All doors, windows, glass partitions, and low furniture that were below eye level were removed. The results were represented by means of local and global integration between two workstations. All values were converted to z-scores for comparison.

\section{Statistical analysis}

Statistical analysis was performed using SPSS 25. Descriptive statistics were conducted to determine means and standard deviations. Spearman correlation analysis was used to examine the strength and the magnitude of the relationships between tested variables. Analysis of variance (t-test and one-way ANOVA) was used to examine group differences. The research used the following estimates to interpret the Spearman correlation coefficient $(\mathrm{r})$ : $(\mathrm{r}=0.00-0.19$ : very weak; $\mathrm{r}=0.20-0.39$, weak; $\mathrm{r}=0.40-0.59$, moderate; $r=0.60-0.79$, strong; and $\mathrm{r}=0.80-1.0$, very strong (Evans, 1996).

\section{RESULTS}

\subsection{Face-to-face communication}

The overall mean scores (Table 1) of the frequency of F2F work-related communication (COM1: $\mathrm{n}=56$; mean= 3.09) and non-work-related communication (COM2: $n=38$; mean=2.24) within the US offices were slightly lower than the mean scores of communication frequencies in Jordanian workplaces (COM1: $\mathrm{n}=83$; mean=3.13) and (COM2: $\mathrm{n}=53$; mean= 3.26). T-test results (Table 1) confirm a significant difference between the US and Jordanian workplaces in the frequency of F2F non-work-related communication ( $\mathrm{t}(89)=-5.190, p<0.001)$, which indicates the F2F social exchange among Jordanian employees is higher than in the US workplaces. 
Table 1. Descriptive and statistical test results of communication data.

\begin{tabular}{|c|c|c|}
\hline Approach & USA workplaces & Jordan workplaces \\
\hline \multicolumn{3}{|l|}{ Social Network Survey } \\
\hline $\begin{array}{l}\text { Office Code: Number of responses }{ }^{\text {a }} \text { (response rate, total staff } \\
\text { members) }\end{array}$ & $\begin{array}{l}\text { A: } 4(33 \%, 12) \\
\text { B: } 5(71 \%, 7)\end{array}$ & $\begin{array}{l}\text { C: } 5(50 \%, 10) \\
\text { D: } 5(42 \%, 12) \\
\text { E: } 8(44 \%, 18) \\
\end{array}$ \\
\hline \multicolumn{3}{|l|}{ Face-to-face work-related "routine work" communication } \\
\hline Data points $^{\mathrm{b}}$ & 56 & 83 \\
\hline $\operatorname{Mean}^{\mathrm{c}}(\mathrm{SD})$ & $3.09(1.15)$ & $3.13(1.1)$ \\
\hline $\begin{array}{l}\text { T-test between the two countries on face-to-face work-related } \\
\text { communication }\end{array}$ & \multicolumn{2}{|c|}{$\mathrm{t}(137)=-0.223, \mathrm{p}=0.824$} \\
\hline \multicolumn{3}{|l|}{$\begin{array}{l}\text { Face-to-face non-work-related "personal interest" } \\
\text { communication }\end{array}$} \\
\hline Data points ${ }^{\mathrm{b}}$ & 38 & 53 \\
\hline Meanc $^{c}$ (SD) & $2.24(0.97)$ & $3.26(0.9)$ \\
\hline $\begin{array}{l}\text { T-test between the two countries on face-to-face non work-related } \\
\text { communication }\end{array}$ & \multicolumn{2}{|c|}{$\mathrm{t}(89)=-5.190, \mathrm{p}<0.001$} \\
\hline \multicolumn{3}{|l|}{ Virtual work-related "routine work" communication } \\
\hline Data points $^{\mathrm{b}}$ & 56 & 83 \\
\hline Mean (SD) & $3.16(1.19)$ & $2.41(1.32)$ \\
\hline $\begin{array}{l}\text { T-test between the two countries on virtual work-related } \\
\text { communication }\end{array}$ & \multicolumn{2}{|c|}{$\mathrm{t}(137)=3.43, \mathrm{p}=0.001$} \\
\hline \multicolumn{3}{|l|}{ Virtual non-work-related "personal interest" communication } \\
\hline Data points ${ }^{\mathrm{a}}$ & 38 & 52 \\
\hline Mean $^{\mathrm{c}}(\mathrm{SD})$ & $1.74(1)$ & $2.37(0.97)$ \\
\hline $\begin{array}{l}\text { T-test between the two countries on virtual non-work-related } \\
\text { communication }\end{array}$ & \multicolumn{2}{|c|}{$\mathrm{t}(88)=-2.989, \mathrm{p}=0.004$} \\
\hline
\end{tabular}

${ }^{a}$ Each data point represents a single individual.

${ }^{\mathrm{b}}$ Each data point represents communication frequency between two individuals.

${ }^{\mathrm{c}}$ Mean scores of communication frequency (on a scale of 1-5), 1: once or twice a month, 2: once or twice a week, 3: about once a day, 4: 2 to 4 times a day, and 5: more than 5 times a day.

\subsubsection{Proximity impacts on F2F communications}

Spearman correlation results (Table 2) demonstrated that distances (DIS) between team members were associated with the frequency of work-related (COM1) and non-work-related communication (COM2) in both US and Jordanian workplaces. However, the relationships range from (negative- weak) to (negative- moderate) linear association: US cases (DIS. COM1: $\mathrm{r}_{\mathrm{s}}=-0.436, \mathrm{n}=56, p=.001$; DIS. COM2: $\mathrm{r}_{\mathrm{s}}=-0.343, \mathrm{n}=38, p=.035$ ) and Jordanian cases (DIS. COM1: $\mathrm{r}_{\mathrm{s}}=-0.501, \mathrm{n}=83, p<.001$; DIS.COM2: $\left.\mathrm{r}_{\mathrm{s}}=-0.435, \mathrm{n}=53, p=.001\right)$. ANOVA results confirm this negative linear relationship between the distance and communication frequency in each country (Table 3 ). A finding confirms that staff members with shorter distances, on average, reported having more frequent face-to-face communication (for both routine-work communication and personal interest communication). 
Table 2. Spearman Correlation analysis

\begin{tabular}{|c|c|c|c|c|c|c|}
\hline & & Distance & $\begin{array}{l}\text { Local } \\
\text { Integration }\end{array}$ & $\begin{array}{l}\text { Global } \\
\text { Integration }\end{array}$ & $\begin{array}{l}\text { Gender } \\
\text { Interaction }\end{array}$ & $\begin{array}{l}\text { Role } \\
\text { Interaction }\end{array}$ \\
\hline \multirow[t]{4}{*}{$\begin{array}{l}\text { USA } \\
\text { workplaces }\end{array}$} & $\begin{array}{l}\text { F2F work-related } \\
\text { communication }\end{array}$ & $-0.436^{* *}$ & $0.423^{* *}$ & $0.373^{* *}$ & -0.023 & 0.056 \\
\hline & $\begin{array}{l}\text { F2F non-work-related } \\
\text { communication }\end{array}$ & $-0.343^{*}$ & $0.314^{*}$ & $0.333^{*}$ & 0.053 & 0.171 \\
\hline & $\begin{array}{l}\text { Virtual work-related } \\
\text { communication }\end{array}$ & $-0.369^{* *}$ & $0.332^{*}$ & $0.280^{*}$ & 0.093 & -0.045 \\
\hline & $\begin{array}{l}\text { Virtual non-work-related } \\
\text { communication }\end{array}$ & 0.105 & 0.048 & 0.014 & $0.362^{*}$ & 0.014 \\
\hline \multirow[t]{4}{*}{$\begin{array}{l}\text { Jordan } \\
\text { workplaces }\end{array}$} & $\begin{array}{l}\text { F2F work-related } \\
\text { communication }\end{array}$ & $-0.501^{* *}$ & $0.258^{*}$ & $0.264^{*}$ & $-0.305^{* *}$ & $-0.403^{* *}$ \\
\hline & $\begin{array}{l}\text { F2F non-work-related } \\
\text { communication }\end{array}$ & $-0.435^{* *}$ & 0.059 & 0.088 & $-0.259^{*}$ & $-0.278^{*}$ \\
\hline & $\begin{array}{l}\text { Virtual work-related } \\
\text { communication }\end{array}$ & $-0.196^{*}$ & $0.394^{* *}$ & $0.398^{* *}$ & -0.056 & $-0.247^{*}$ \\
\hline & $\begin{array}{l}\text { Virtual non-work-related } \\
\text { communication }\end{array}$ & -0.080 & -0.066 & -0.060 & 0.161 & -0.044 \\
\hline
\end{tabular}

** Correlation is significant at the 0.01 level (2-tailed).

* Correlation is significant at the 0.05 level (2-tailed).

\subsubsection{Visibility impacts on F2F communications.}

Spearman correlation results demonstrated that the mean values of local integration (INT-R3) and global integration (INT-RN) were associated with the frequency of work-related communication (COM1) in the US and Jordanian workplaces. However, the relationships range from (positive- very weak) to (positive- weak) linear association: US cases (INT-R3. COM1: $\mathrm{r}_{\mathrm{s}}=0.423, \mathrm{n}=56, p=.001$; and INT-RN. COM1: $\mathrm{r}_{\mathrm{s}}=0.373, \mathrm{n}=56, p=.005$ ) and Jordanian cases (INT-R3. COM1: $\mathrm{r}_{\mathrm{s}}=0.258, \mathrm{n}=83, p=.019$; and INT-RN. COM1: $\mathrm{r}_{\mathrm{s}}=0.264, \mathrm{n}=83, p=.016$ ). Similarly, values of local integration (INT-R3) and global integration (INT-RN) between any two workstations have weak correlations with the frequency of non-work-related communication (COM1) in the US workplaces (INT-R3. COM2: $\mathrm{r}_{\mathrm{s}}=0.314, \mathrm{n}=38$, $p=.05$; and INT-RN. COM2: $\mathrm{r}_{\mathrm{s}}=0.333, \mathrm{n}=38, p=.041$ ). These positive linear associations have been confirmed with ANOVA analysis (Table 3). Overall, visibility values determine the frequency of communications in US workplaces than in Jordanian workplaces.

\subsection{Virtual communication}

The overall mean scores of virtual work-related communication (COM1: $n=56$; mean= 3.09) in US workplaces are higher than in Jordanian workplaces (COM1: $\mathrm{n}=56$; mean=3.09). On the other hand, the mean values of nonwork-related communication (COM2: $\mathrm{n}=38$; mean= 2.24) within the US offices were lower than the mean scores of communications in Jordanian workplaces (COM1: $\mathrm{n}=83$; mean=3.13). T-test results (Table 1) confirm a significant difference between US and Jordanian workplaces in the frequency of virtual work-related $(\mathrm{t}(137)=3.43, p=0.001)$ and non-work-related communication ( $\mathrm{t}(88)=-2.989, p=0.004)$. This reflects the propensity of US employees in the USA offices for using electronic communication tools in work-related communication. On the other hand, Jordanian workplaces tend to use virtual communication tools for social exchange and non-work-related communications. 


\subsubsection{Proximity impacts on virtual communications}

The Spearman correlation (Table 2) results demonstrated that distances (DIS) between workstations were associated negatively with the frequency of virtual work-related communication (COM1) in both US (DIS. COM1: $r_{s}=-0.369$, $\mathrm{n}=56, p=.005$ ) and Jordanian workplaces (DIS. COM1: $\mathrm{r}_{\mathrm{s}}=-0.196, \mathrm{n}=83, p=.05$ ). On the other hand, there is no correlation between distance values and virtual non-work-related communication. These results are also confirmed using the ANOVA test (Table 3). Shorter distances stimulate more virtual work-related communications.

\subsubsection{Visibility impacts on virtual communications.}

Visibility measures were found to have a positive association with the frequency of work-related communications in the US (INT-R3. COM1: $\mathrm{r}_{\mathrm{s}}=0.332, \mathrm{n}=56, p=.012$; and INT-RN. COM1: $\mathrm{r}_{\mathrm{s}}=0.280, \mathrm{n}=56, p=.037$ ) and Jordanian workplaces (INT-R3. COM1: $\mathrm{r}_{\mathrm{s}}=0.394, \mathrm{n}=83, p<.001$; and INT-RN. COM1: $\mathrm{r}_{\mathrm{s}}=0.398, \mathrm{n}=83, p<.001$ ). On the other hand, there was no significant impact of visibility values on non-work-related communication in US and Jordanian workplaces. These results are also confirmed by the ANOVA test (Table 3).

Table 3. ANOVA and post hoc Tukey HSD results.

\begin{tabular}{|c|c|c|}
\hline Approach & USA workplaces & Jordan workplaces \\
\hline \multicolumn{3}{|l|}{ ANOVA test for distance vs face-to-face communication } \\
\hline $\begin{array}{l}\text { Differences of mean distances per face-to-face work-related } \\
\text { communication frequency }\end{array}$ & $\begin{array}{l}\mathrm{F}(4,51)=5.14 \\
p=0.001\end{array}$ & $\begin{array}{l}\mathrm{F}(4,78)=5.70, \\
p<0.001\end{array}$ \\
\hline Tukey HSD significant pairs of frequency categories $(\mathrm{p}<.05)$ & $1-4,2-4,3-4$ & $1-4,1-5,2-4,2-5$ \\
\hline $\begin{array}{l}\text { Differences of mean distances per face-to-face non-work-related } \\
\text { communication frequency }\end{array}$ & $\begin{array}{l}\mathrm{F}(3,34)=4.43 \\
p=0.01\end{array}$ & $\begin{array}{l}\mathrm{F}(3,49)=5.71, \\
p=0.002\end{array}$ \\
\hline Tukey HSD significant pairs of frequency categories $(\mathrm{p}<.05)$ & $1-4,1-5$ & $2-3,2-4,2-5$ \\
\hline \multicolumn{3}{|l|}{ ANOVA test for visibility vs face-to-face communication } \\
\hline $\begin{array}{l}\text { Differences of mean visibility (local integration) per face-to-face } \\
\underline{\text { work-related communication frequency }}\end{array}$ & $\begin{array}{l}\mathrm{F}(4,38.7)=4.79 \\
p=0.001^{\mathrm{a}}\end{array}$ & $\begin{array}{l}\mathrm{F}(4,78)=1.92, \\
p=0.115\end{array}$ \\
\hline Tukey HSD significant pairs of frequency categories $(\mathrm{p}<.05)$ & $1-2,1-3,1-4,1-5$ & N.A. \\
\hline $\begin{array}{l}\text { Differences of mean visibility (global integration) per face-to-face } \\
\text { work-related communication frequency }\end{array}$ & $\begin{array}{l}\mathrm{F}(4,34.7)=4.92 \\
p=0.001^{\mathrm{a}}\end{array}$ & $\begin{array}{l}\mathrm{F}(4,78)=1.96 \\
p=0.109\end{array}$ \\
\hline Tukey HSD significant pairs of frequency categories $(\mathrm{p}<.05)$ & $1-3,1-4,1-5$ & N.A. \\
\hline $\begin{array}{l}\text { Differences of mean visibility (local integration) per face-to-face } \\
\text { non-work-related communication frequency }\end{array}$ & $\begin{array}{l}\mathrm{F}(3,34)=3.39 \\
p=.001\end{array}$ & $\begin{array}{l}\mathrm{F}(3,49)=1.71, \\
p=.177\end{array}$ \\
\hline Tukey HSD significant pairs of frequency categories $(\mathrm{p}<.05)$ & $1-4,1-5$ & N.A. \\
\hline $\begin{array}{l}\text { Differences of mean visibility (global integration) per face-to-face } \\
\text { non-work-related communication frequency }\end{array}$ & $\begin{array}{l}\mathrm{F}(3,26.3)=2.88 \\
p=.027^{\mathrm{a}}\end{array}$ & $\begin{array}{l}\mathrm{F}(3,49)=1.71, \\
p=.178\end{array}$ \\
\hline Tukey HSD significant pairs of frequency categories $(\mathrm{p}<.05)$ & N.A. & NA \\
\hline
\end{tabular}




\begin{tabular}{|c|c|c|}
\hline ANOVA test for distance vs virtual communication & & \\
\hline $\begin{array}{l}\text { Differences of mean distances per virtual work-related } \\
\text { communication frequency }\end{array}$ & $\begin{array}{l}\mathrm{F}(4,51)=2.74, \\
p=.039\end{array}$ & $\begin{array}{l}\mathrm{F}(4,78)=2.50, \\
p=.049\end{array}$ \\
\hline Tukey HSD significant pairs of frequency categories $(\mathrm{p}<.05)$ & N.A. & N.A. \\
\hline $\begin{array}{l}\text { Differences of mean distances per virtual non-work-related } \\
\text { communication frequency }\end{array}$ & $\begin{array}{l}\mathrm{F}(3,34)=1.21, \\
p=.321\end{array}$ & $\begin{array}{l}\mathrm{F}(4,47)=.587, \\
p=.673\end{array}$ \\
\hline Tukey HSD significant pairs of frequency categories $(\mathrm{p}<.05)$ & N.A. & NA \\
\hline ANOVA test for visibility vs virtual communication & & \\
\hline $\begin{array}{l}\text { Differences of mean visibility (local integration) per virtual work- } \\
\text { related communication frequency }\end{array}$ & $\begin{array}{l}\mathrm{F}(4,51)=2.56, \\
p=0.05\end{array}$ & $\begin{array}{l}\mathrm{F}(4,44.8)=5.24, \\
p=0.001^{\mathrm{a}}\end{array}$ \\
\hline Tukey HSD significant pairs of frequency categories $(\mathrm{p}<.05)$ & N.A. & $1-5,2-4,2-5,3-5$ \\
\hline $\begin{array}{l}\text { Differences of mean visibility (global integration) per virtual } \\
\text { work-related communication frequency }\end{array}$ & $\begin{array}{l}\mathrm{F}(4,51)=2.62, \\
p=.046\end{array}$ & $\begin{array}{l}\mathrm{F}(4,45.2)=5.21, \\
p=0.001^{\mathrm{a}}\end{array}$ \\
\hline Tukey HSD significant pairs of frequency categories $(\mathrm{p}<.05)$ & N.A. & $1-4,1-5,2-4,2-5$ \\
\hline $\begin{array}{l}\text { Differences of mean visibility (local integration) per virtual non- } \\
\text { work-related communication frequency }\end{array}$ & $\begin{array}{l}\mathrm{F}(3,34)=.271, \\
p=0.85\end{array}$ & $\begin{array}{l}\mathrm{F}(4,47)=2.51, \\
p=0.054\end{array}$ \\
\hline Tukey HSD significant pairs of frequency categories $(\mathrm{p}<.05)$ & N.A. & N.A. \\
\hline $\begin{array}{l}\text { Differences of mean visibility (global integration) per virtual non- } \\
\underline{\text { work-related communication frequency }}\end{array}$ & $\begin{array}{l}\mathrm{F}(3,34)=.186, \\
p=0.91\end{array}$ & $\begin{array}{l}\mathrm{F}(4,47)=2.27, \\
p=0.075\end{array}$ \\
\hline Tukey HSD significant pairs of frequency categories $(\mathrm{p}<.05)$ & N.A. & N.A. \\
\hline
\end{tabular}

${ }^{a}$ An adjusted $\mathrm{F}$ test was performed using Brown-Forsythe statistic since an assumption of homogeneity of variance was not met.

\subsection{Communication characteristics}

\subsubsection{Communication between team members based on gender.}

The results (Figure 5) showed that the same gender peer communications (COM 1 and COM2) were higher in Jordanian cases (COM1: 57.8\%; COM2: 62.3\%) in comparison with US cases (COM1: 55.4\%; COM2: 55.3\%), whereas different gender peer communications were higher in US offices (COM1: 44.6\%; COM2: 44.7\%) than in the Jordanian cases (COM1: 42.2\%; COM2: 37.7\%). Communication in Jordanian workplaces is significantly related to the type of gender, where the frequency of F2F work-related and non-work-related communications increased within same-gender (COM1: $\mathrm{r}_{\mathrm{s}}=-0.305, \mathrm{n}=83, p=.005$; and COM2: $\left.\mathrm{r}_{\mathrm{s}}=-0.259, \mathrm{n}=53, p=.05\right)$. 

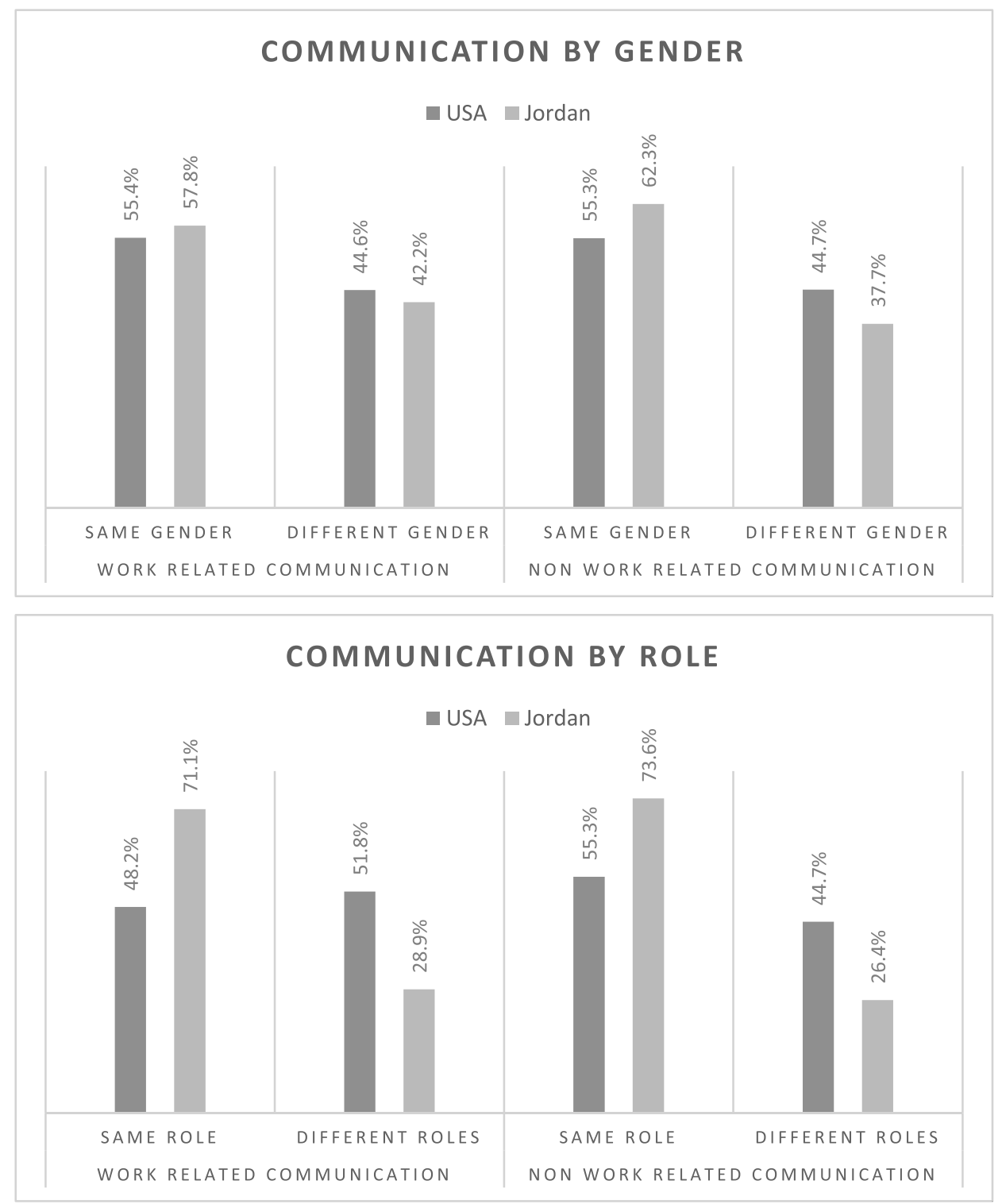

Figure 5. Percentages of Same-Gender Vs. Different Gender Communications (top), and Same Role Vs. Different Role Communications (bottom) in USA and Jordanian workplaces: higher frequencies of the same gender and same role communication in Jordanian workplaces.

\subsubsection{Communication between team members based on the role.}

The results (Figure 5) showed that the same-role communications were higher in the Jordanian cases (COM1: 71.1\%; COM2: 73.6\%) in comparison with the US cases (COM1: 48.2\%; COM2: 55.3\%), whereas different-role communications were higher in US offices (COM1: 51.8\%; COM2: 44.7\%) than in the Jordanian cases (COM1: 28.9\%; COM2: 26.4\%). The Spearman correlation results reported a significant association between communication and staff role in Jordanian workplaces. The frequency of F2F communication increases between team members of the same role (COM1: $\mathrm{r}_{\mathrm{s}}=-0.403, \mathrm{n}=83, p<.001$; and COM2: $\mathrm{r}_{\mathrm{s}}=-0.278, \mathrm{n}=53, p=.024$ ), whereas, in the US offices, there is no significant association between communication and staff role. 


\section{DISCUSSION}

An evidence-based design aims to understand the nature of human behavior in designed environments so that design decisions are based on well-informed research evidence. This evidence comes in the form of studying patterns of human behavior influenced by many properties of space. Accordingly, this allows designers to understand what configurations of the space derive organizational outcomes (e.g., greater communication) when designing new environments.

This paper aims to contribute to the organizational design literature by analyzing how co-working spaces facilitate communication and exchange of work-related and non-work-related information. In particular, this study is among the first to compare the impacts of proximity, visibility, and two of the communication characteristics (gender-based and role-based communications) on knowledge and information exchange in two different cultures. We found that the proximity of workstations facilitated patterns of F2F and virtual communication. The study found that locating workstations of staff members next to each other may increase their communication frequency. This finding is consistent with previous research findings (Allen, 2007; Kabo, 2017). Visibility between team members can support interactions. However, these associations have a weak strength.

The nature of similarity relationships and the impacts of a workplace-related culture on communication was another focus of this research. The results revealed that similarity (same gender and same role) is an essential factor in increasing Jordanian workplaces' communication frequencies. As Hofstede (2001) explained, in societies with clear vertical hierarchical systems - as in middle eastern societies - people are more likely to connect with persons who are similar to themselves.

Both in-person and electronic encounters are reported in workplaces. However, there are some obvious differences in use. Our results suggest that team members rely more on face-to-face interaction than electronically based communication tools. Higher frequencies of non-work-related communication are mediated through face-to-face interaction, especially in workplaces.

\section{IMPLICATIONS AND LIMITATIONS}

For many organizations who are rethinking and redesigning their work environments, these findings have significant implications. In a practice evolving towards team-based work and coworking spaces, premium attention should be placed on proximity as a key design strategy. While the renovation of an entire office may be unattainable due to cost or constraints of existing architecture, reconfiguration of furniture layout and the reassignment of workstations can be done in existing spaces to provide visual and physical connections between staff members. Designers of workplaces should consider the characteristics of team members and the related culture of the workplace. Managers should take into account the integration of electronic tools, such as smartphones, with traditional means of communication and knowledge exchange.

This study naturally has strengths and weaknesses that may impact the results. We explored the communication networks in small teams in five workplaces, limiting the generalizability of the findings. Additional studies are encouraged to explore whether similar findings are obtained with other teams with bigger sizes and settings. A second weakness is that our analysis focused on communication interactions in small architecture firms but did not consider other types of firms or departments. Our empirical analysis has methodological limitations. Although we examined some variables that characterize dyadic communication, other variables impact communication, such as task configuration, seating arrangements, environmental factors, etc., that we did not identify. Advanced statistical methods for analysis should be applied to the study of interpersonal networks (e.g., Mascia, Rinninella, Pennacchio, Cerrito, and Gasbarrini (2019)). Thus, our study cannot enable claims of causality. Notwithstanding the limitations noted above, this study provides a novel contribution to the organizational design literature, explaining how team members rely on different types and tools of communication and how the physical layout and related culture could influence the relationships between team members and their communication networks. Implementing the proposed concepts helps to develop sustainable office buildings that reduce minimize negative impacts of the built environment on staff members. Developing more sustainable work environment helps to achieve long-term growth in different organizational, social, and economic aspects (Alsulaihi, 2017). 


\section{REFERENCES}

Allen, T.J. 2007. Architecture and communication among product development engineers. California Management Review, 49(2): $23-41$.

Alsulaihi, I.A. 2017. Developing a rating system for sustainable office buildings using Simos' procedure. Journal of Engineering Research, 5(1).

Appel-Meulenbroek, R., de Vries, B., \& Weggeman, M. 2017. Knowledge sharing behavior: the role of spatial design in buildings. Environment and Behavior, 49(8): 874-903.

Becker-Beck, U., Wintermantel, M., \& Borg, A. 2005. Principles of regulating interaction in teams practicing face-to-face communication versus teams practicing computer-mediated communication. Small group research, 36(4): 499-536.

Bernstein, E.S., \& Turban, S. 2018. The impact of the 'open'workspace on human collaboration. Philosophical Transactions of the Royal Society B: Biological Sciences, 373(1753): 20170239.

Bordia, P. 1997. Face-to-face versus computer-mediated communication: A synthesis of the experimental literature. The Journal of Business Communication (1973), 34(1): 99-118.

Evans, J.D. 1996. Straightforward statistics for the behavioral sciences: Thomson Brooks/Cole Publishing Co.

Festinger, L., Schachter, S., \& Back, K. 1950. Social pressures in informal groups; a study of human factors in housing.

Gharaveis, A., Hamilton, D.K., \& Pati, D. 2018. The impact of environmental design on teamwork and communication in healthcare facilities: A systematic literature review. HERD: Health Environments Research \& Design Journal, 11(1): 119-137.

Gharaveis, A., Hamilton, D.K., Pati, D., \& Shepley, M. 2018. The impact of visibility on teamwork, collaborative communication, and security in emergency departments: An exploratory study. HERD: Health Environments Research \& Design Journal, 11(4): 37-49.

Gudykunst, W.B., Ting-Toomey, S., \& Chua, E. 1988. Culture and interpersonal communication: Sage Publications, Inc.

Hillier, B., \& Hanson, J. 1989. The social logic of space: Cambridge university press.

Hoegl, M., \& Proserpio, L. 2004. Team member proximity and teamwork in innovative projects. Research policy, 33(8): 11531165.

Hofstede, G. 2001. Culture's consequences: Comparing values, behaviors, institutions and organizations across nations: Sage publications.

Hollingshead, A.B., McGrath, J.E., \& O'Connor, K.M. 1993. Group task performance and communication technology: A longitudinal study of computer-mediated versus face-to-face work groups. Small group research, 24(3): 307-333.

House, J.S., \& Wells, J.A. 1978. Occupational stress, social support, and health. Paper presented at the Reducing occupational stress: Proceedings of a conference.

Kim, J., \& De Dear, R. 2013. Workspace satisfaction: The privacy-communication trade-off in open-plan offices. Journal of Environmental Psychology, 36: 18-26.

Kratzer, J., Leenders, R.T.A., \& Van Engelen, J.M. 2005. Informal contacts and performance in innovation teams. International Journal of Manpower, 26(6): 513-528.

Mascia, D., Rinninella, E., Pennacchio, N.W., Cerrito, L., \& Gasbarrini, A. 2019. It's how we communicate! Exploring faceto-face versus electronic communication networks in multidisciplinary teams. Health care management review.

McPherson, M., Smith-Lovin, L., \& Cook, J.M. 2001. Birds of a feather: Homophily in social networks. Annual review of sociology, 27(1): 415-444.

Nardi, B.A., \& Whittaker, S. 2002. The place of face-to-face communication in distributed work. Distributed work, 83-110.

Penn, A., Desyllas, J., \& Vaughan, L. 1999. The space of innovation: interaction and communication in the work environment. Environment and planning B: Planning and design, 26(2): 193-218.

Peponis, J., Bafna, S., Bajaj, R., Bromberg, J., Congdon, C., Rashid, M., . . . Zimring, C. 2007. Designing space to support knowledge work. Environment and Behavior, 39(6), 815-840. 
Sailer, K., \& Penn, A. 2009. Spatiality and transpatiality in workplace environments.

Sundstrom, E., Town, J.P., Brown, D.W., Forman, A., \& Mcgee, C. 1982. Physical enclosure, type of job, and privacy in the office. Environment and Behavior, 14(5): 543-559.

Tillema, T., Dijst, M., \& Schwanen, T. 2010. Face-to-face and electronic communications in maintaining social networks: the influence of geographical and relational distance and of information content. New media \& society, 12(6): 965-983.

Turner, A. 2011. UCL Depthmap: spatial network analysis software, version 10. University College London, VR Centre of the Built Environment, London, 150, 2011.

Wineman, J.D., Kabo, F.W., \& Davis, G.F. 2009. Spatial and Social Networks in Organizational Innovation. Environment and Behavior, 41(3): 427-442. doi:10.1177/0013916508314854 